\title{
Analisis SWOT/TOWS Untuk Perencanaan Strategis Sistem Informasi dan Teknologi Informasi Pada SMK di Kota Lubuklinggau
}

\author{
Okto Kurnia \\ STMIK Musi Rawas \\ Email: okto_kurnia@yahoo.com
}

\begin{abstract}
Currently, information and communication technology (ICT) has become an important sector for administering education in schools. The use of Information and Communication Technology is one of the determining aspects in competition. The condition of ICT in Vocational High Schools (SMK) in Lubuklinggau City has not fully used ICT-based applications, several schools that already have ICT applications and infrastructure are built themselves and are managed according to local needs both in the administration section and the support units. Meanwhile, on the other hand, there are still aspects of the public that are not yet based on ICTs with inadequate ICT facilities / infrastructure to support the success of organizational goals in the field of education optimally. For this reason, the researcher wants to help the Education Office of the City of Lubuklinggau to plan a technology strategy and information system that can be used as a guide in the ICT strategic plan. This study uses the SWOT / TOWS matrix as one of the methods applied for internal analysis in order to produce strategic planning proposals for ICT development for vocational schools in Lubuklinggau City.
\end{abstract}

Keywords: planning, strategic, information and communication technology, SWOT/TOWS.

\section{Pendahuluan}

Globalisasi yang terjadi saat ini di dunia pendidikan, lingkungan sosial, ekonomi, teknologi, sampai politik mengharuskan dunia pendidikan memikirkan kembali bagaimana perubahan tersebut mempengaruhinya sebagai sebuah institusi sosial dan bagaimana harus berinteraksi dengan perubahan tersebut. Salah satu perubahan lingkungan yang sangat mempengaruhi dunia pendidikan adalah hadirnya Sistem Informasi dan Teknologi Informasi (SI/TI). Perkembangan Sistem informasi dan teknologi informasi ini diharapkan dapat mempermudah manusia dalam melakukan aktivitas, meningkatkan kinerja, memungkinkan berbagai kegiatan dapat dilaksanakan dengan cepat, tepat, dan akurat, dengan tujuan meningkatkan produktifitas.

Kondisi teknologi dan sistem informsi pada SMK di Kota Lubuklinggau saat ini belum sepenuhnya menggunakan aplikasi yang berbasis TIK, beberapa sekolah yang sudah memiliki aplikasi dan infrastruktur TIK di bangun sendiri dan di kelolah sesuai kebutuhan local baik pada bagian tata usaha maupun unit-unit pendukung. Sementara pada sisi lain justru masih terdapat aspek-aspek yang belum berbasis TIK, dengan sarana/prasarana TIK yang tidak memadai untuk menunjang keberhasilan tujuan organisasi di bidang pendidikan dan kecenderungan kedepan terdapat peningkatan yang signifikan terhadap kebutuhan pengumpulan, penyimpanan dan pendistribusian informasi dalam jumlah besar dan cepat. Kondisi tersebut diantaranya menyebabkan perlunya penyusunan perencanaan strategis agar perencaan dan implementasi TIK di lingkungan SMK di Kota Lubuklinggau mampu memenuhi kebutuhan organisasi di masa yang akan datang.

Untuk menghasilkan rencana strategis teknologi dan sistem informasi yang baik maka di perlukan SWOT sebagai analisis awal untuk memperoleh gambaran kondisi yang ada di SMK

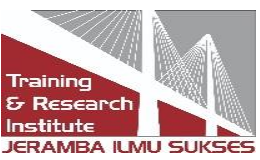


Kota Lubulinggau. Analisis SWOT merupakan salah satu metode analisis dalam manajemen strategis yang sudah terbukti sangat berguna untuk mengindentifikasi kompetensi suatu organisasi dan mengindentifikasi peluang yang tersedia. Menurut Freddy Rangkuti (2009: 18), analisis SWOT adalah identifikasi berbagai faktor secara sistematis untuk merumuskan strategi perusahaan. Analisis ini didasarkan pada logika yang dapat memaksimalkan kekuatan (strengths), dan peluang (opportunities), namun secara bersamaan meminimalkan kelemahan (weaknesses) dan ancaman (threats).

\section{Tinjauan Literatur}

\subsection{Hubungan Antara Strategi Bisnis, Strategi SI dan Strategi TI}

Strategi sistem informasi dan teknologi informasi saat ini lebih mengidentifikasikan persoalan teknologi dan terminology teknikal saja, tapi sedikit mengidentifikasikan kebutuhan organisasi akan aplikasi dan kebutuhan bisnis. Earl menyarankan agar strategi SI fokus dalam mengidentifikasi kebutuhan perusahaan terhadap teknologi informasi (application set) dan strategi TI fokus dalam mengidentifikasi kebutuhan perusahaan terhadap teknologi informasi dan infrastrukturnya (Antoni, Akbar \& Fatoni, 2018; Antoni, Fikari, Akbar \& Jie, 2018; Akbar \& Antoni, 2019; Ariana, Azim \& Antoni, 2020; Antoni, Jie \& Abareshi, 2020). Hubungan ini dapat digambarkan seperti gambar dibawah ini :

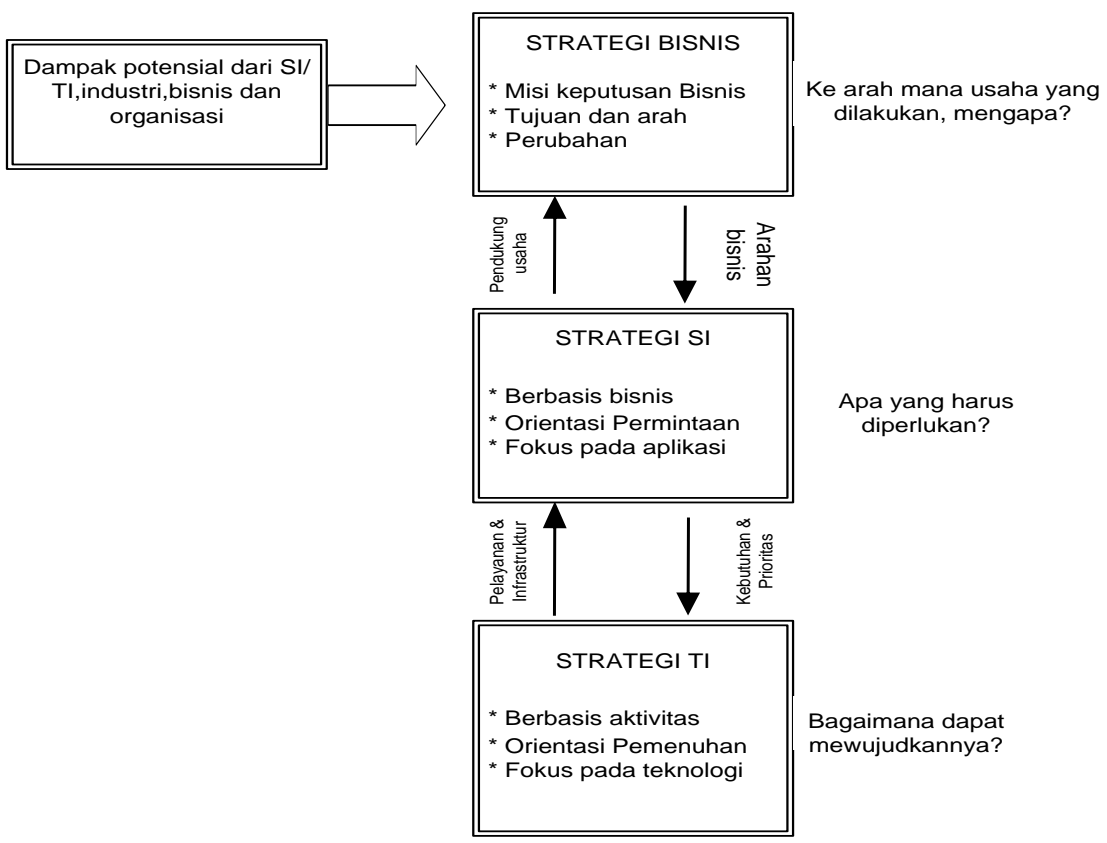

Gambar 1. Hubungan antara Strategi Bisnis, Strategi SI, dan Strategi TI (Ward \& Peppard, 2002)

\subsection{Perencanaan Strategi SI/TI}

perencanaan strategis sistem informasi dan teknologi informasi menjelaskan berbagai tools, teknik, dan kerangka kerja bagi manajemen untuk menyelaraskan strategi sistem informasi dan teknologi informasi dengan strategi bisnis, bahkan mencari kesempatan baru melalui penerapan teknologi yang inovatif (Ward \& Peppard, 2002). 


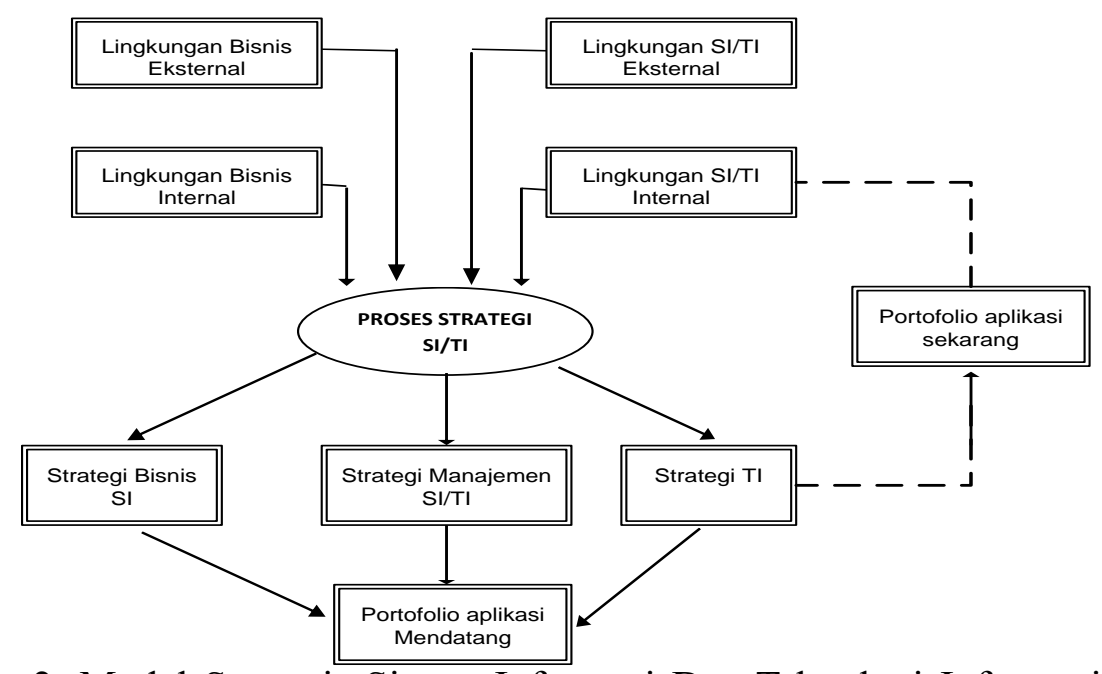

Gambar 2. Model Strategis Sistem Informasi Dan Teknologi Informasi (Ward and Peppard, 2002)

Pada penelitian ini metode yang digunakan adalah metode deskriptif dengan pendekatan studi kasus, analisis dan evaluasi dengan studi literature terhadap dokumen-dokumen organisasi berkenaan dengan strategi organisasi, rencana manajerial operasional dan penggunaan sistem informasi dan teknologi informasi yang ada pada organisasi. Perancangan Rencana Strategis Sistem Informasi pada peneitian ini mengacu pada metodologi Perencanaan Strategis yang dikemukakan oleh John Ward, et al dalam bukunya Strategic Planning for Information System.

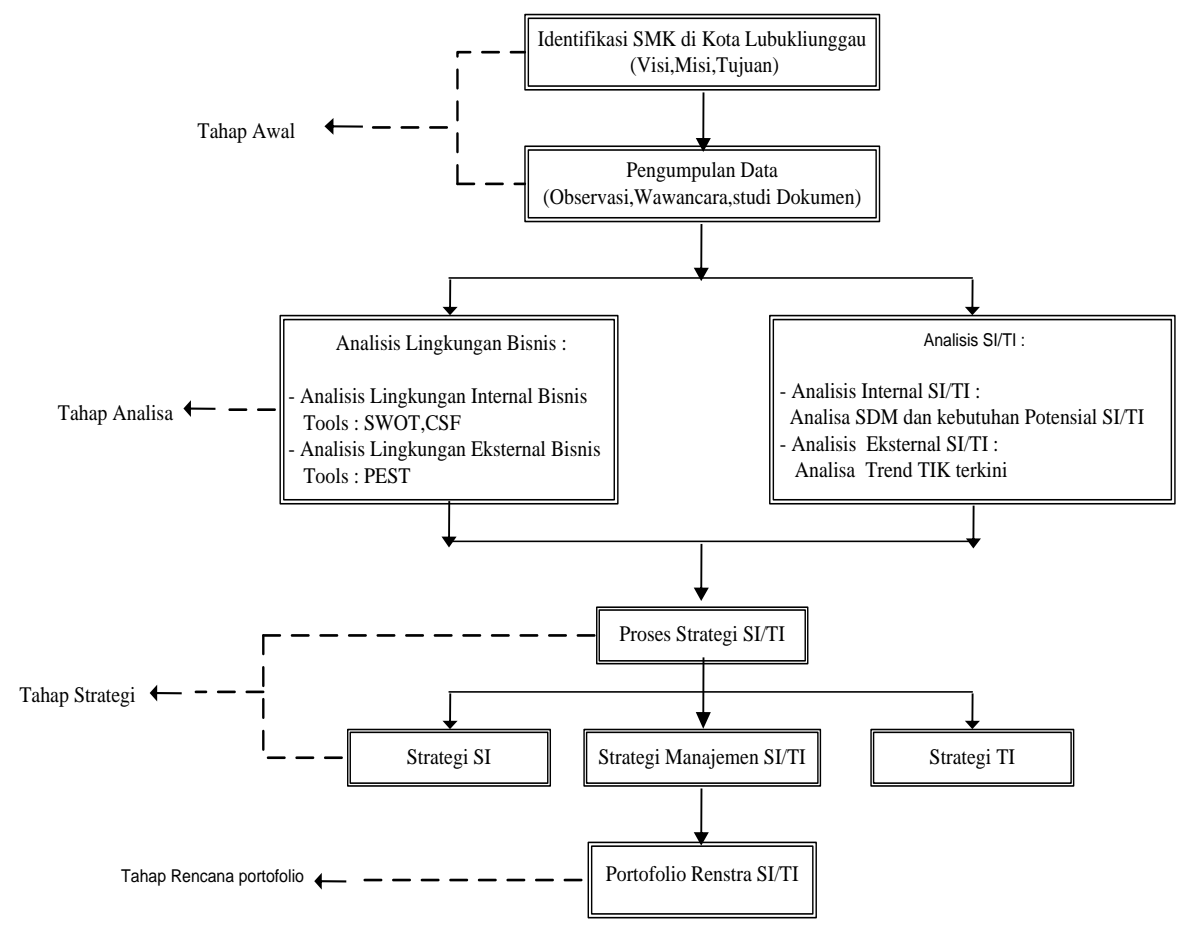

Gambar 3. Kerangka Berpikir

Rencana Strategi SI/IT pada SMK di Kota Lubuklinggau 
1. Identifikasi SMK di Kota Lubuklinggau

Tujuan dari tahap ini adalah untuk mencari informasi sedetail mungkin tentang SMK di Kota Lubuklinggau. Hal-hal yang perlu dicari adalah:

a. Latar Belakang (Visi, Misi, dan Tujuan)

b. Struktur Organisasi, Pembagian Tugas dan tanggung jawab serta keragaan sumber daya manusia masing-masing divisi.

c. Proses bisnis di SMK Kota Lubuklinggau.

2. Analisis Lingkungan Eksternal Bisnis

Analisis ini merupakan analisis terhadap faktor-faktor eksternal yang mempengaruhi strategi bisnis SMK di Kota Lubuklinggau, baik peluang maupun ancaman. Analisis ini mencakup :

a. Analisis SWOT (OT)

b. Analisis PEST

3. Analisis Lingkungan Internal Bisnis

Analisis ini merupakan analisis lingkungan internal bisnis yang mempengaruhi, baik kekuatan internal SMK yang harus digali sehingga peluang yang ada dapat dimanfaatkan sebaik mungkin, atau kelemahann yang harus diperbaiki agar tidak menjadi ancaman dikemudian hari. Analisis ini dilakukan mencakup :

a. Analisis SWOT (SW)

4. Analisis Lingkungan Eksternal SI/TI

Analisis terhadap lingkungan eksternal SI/TI merupakan analisis terhadap aspek-aspek eksternal dari sisi SI/TI yang dapat mempengaruhi perancangan perencanaan strategis. Misalnya trend perkembangan teknologi saat ini yang sedang banyak digunakan dan dibutuhkan oleh masyarakat. Tren penggunaan teknologi terbaru sehingga lebih unggul.

5. Analisis Lingkungan Internal SI/TI

Analisis ini merupakan analisis penggunaan dan pemanfaatan teknologi informasi dalam lingkungan internal SMK di Kota Lubuklinggau. Termasuk didalamnya analisis penggunaan teknologi informasi dalam setiap area fungsi bisnis, analisis semua aplikasi yang digunakan dan menyusun portofolio aplikasi sesuai dengan kategori-nya, serta analisis sarana dan prasarana teknologi informasi.

a. Analisis pemanfaatan TI setia area fungsi

Analisis ini meliputi :

1) Area fungsi adalah divisi yang ada di SMK

2) Fungsi bisnis adalah tugas masing-masing divisi

3) Proses bisnis adalah proses dalam melaksanakan fungsi bisnis

4) Peranan SI/TI adalah pemanfaatan TI

b. Analisis Sarana dan Prasarana

Analisis sarana dan prasarana merupakan suatu kegiatan mendokumentasikan seluruh inventaris TI yang ada di SMK, yang terdiri dari :

1) Hardware: spesifikasi komputer, laptop, server

2) Software : List jenis dan jumlah software yang digunakan

3) Network (topologi jaringan, analisis trafic jaringan)

6. Future Business

Tahapan ini merupakan output dari analisis internal dan eksternal SMK di Kota Lubuklingau, yaitu penggabungan hasil analisis visi dan misi SMK dengan tren bisnis saat ini. Sehingga yang akan di paparkan :

a. Jenis Future business 
b. Kelebihan jenis future business tersebut

c. Cara agar dapat memenuhi future business tersebut

d. Strategi Sistem Informasi (SI)

7. Output dari tahap ini adalah list aplikasi atau solusi untuk masing-masing permasalahan yang ada. Tahapannya adalah :

\section{Strategi SI:}

Definisi Masalah \& Alternatif Solusi

Kelebihan \& Kelemahan Tiap Alternatif

Perkiraan Biaya Tiap Masalah

Scoring Tiap Alternatif Solusi

Dapatkan Solusi Tiap Masalah

Gambar 4. Tahapan Strategi Sistem Informasi (SI)

8. Strategi Teknologi Informasi (TI)

Tujuan dari tahap ini adalah untuk manghasilkan suatu rekomendasi spesifikasi kebutuhan TI untuk mendukung usulan aplikasi yang telah diperoleh pada strategi sistem informasi (SI). Langkah-langkah yang perlu dikerjakan adalah :

Strategi TI:

Definisi kebutuhan HW \& SW

Definisi spesifikasi komputer

Definisi spesifikasi server

Definisi spesifikasi Network Device

Definisi Topologi jaringan baru

Gambar 5. Tahapan strategi teknologi informasi (TI)

9. Strategi Manajemen SI/TI

Strategi manajemen SI/TI adalah strategi yang menjamin konsistensi kebijakan yang diambil oleh pihak manajemen yang berkaitan dengan sistem dan teknologi informasi yang akan diimplementasikan (Hoga dan Harisno, 2014). Kebjakan tersebut bisa berupa struktur organisasi yang dapat mendukung sistem informasi pada SMK. Tahapannya adalah :

Strategi Manajemen SI/TI

List SDM yang dibutuhkan

Definisi penambahan SDM Overall

Definisi kualitas dan tanggung jawab

Analisis pemanfaatan TI pada area fungsi

\section{Gambar 6. Tahapan Strategi Manajemen SI/TI}

10. Rekomendasi Portofolio Aplikasi

Portofolio aplikasi masa depan merupakan penjabaran dari aplikasi yang direkomendasikan untuk digunakan oleh organisasi SMK Negeri di masa yang akan datang setelah melakukan analisis terhadap semua lingkungan internal maupun internal dalam software.

11. Rencana Implementasi

Setelah semua tahap analisis dan perancangan strategi selesai, saatnya untuk tahap perencanaan implementasi semua strategi yang telah disusun. Tahapan ini perlu dilakukan dalam merencanakan implementasi dapat dilihat pada gambar berikut : 
Rencana Implementasi :

Jadwal aplikasi, SDM, Teknologi

Defnisi detail budgeting implementasi

Gambar 7. Tahapan Rencana Implementasi

Penelitian dilakukan di pada 3 SMK di Kota Lubuklinggau, SMK N 3 Lubuklinggau, SMK Muhammadiyah, dan SMK Yadika. Dimana saat ini SMK yang ada belum sepenuhnya memanfaatkan teknologi informasi. Maka dari itu diperlukan adanya perencanaan strategis sistem informasi dan teknologi informasi guna meningkatkan mutu dan kualitas SMK yang ada di Kota Lubuklinggau.

\section{Metode Penelitian}

Penelitian ini menggunakan analisis deskriptif kualitatif. Data yang digunakan adalah data primer melalui kuesioner dan wawancara (Fauzi, Dencik \& Asiati, 2019). Penelitian dilakukan pada SMK di Kota Lubuklinggau. Metode analisis menggunakan SWOT/TWOS. Analisis SWOT ini merupakan analisis yang melihat dari sisi Strength atau kekuatan organisasi, Weakness atau kelemahan organisasi, Opportunity atau peluang dan Threat atau ancaman organisasi. Masukan dari proses ini adalah hasil wawancara kepada pimpinan setiap unit organisasi dan melakukan observasi terhadap teknologi informasi yang dimiliki oleh organisasi saat ini, maka diperoleh :

\section{Hasil dan Pembahasan}

\subsection{Analisis SWOT}

Masukan dari proses ini adalah hasil wawancara kepada pimpinan setiap unit organisasi dan melakukan observasi terhadap teknologi informasi yang dimiliki oleh organisasi saat ini, maka diperoleh :

\section{Kekuatan (Strengths)}

a. Telah tersedianya Infrastruktur Teknologi Informasi dan Komunikasi di Lingkungan Sekolah pada Dinas Pendidikan Kota Lubuklinggau

b. Kepedulian, semangat dan dukungan dari pimpinan Instansi, unit-unit pendukung dan pimpinan unit pelaksana teknis dan sarana Sekolah menengah terhadap pengembangan teknologi informasi dan komunikasi.

c. Dukungan pendanaan yang memadai dalam investasi dan pemeliharaan dibidang teknologi informasi dan komunikasi.

2. Kelemahan (Weakness)

a. penggunaan jaringan komputer masih kurang dimanfaatkan dalam mendukung pembelajaran

b. Pemanfaatan website yang tidak optimal

c. penggunaan jaringan komputer masih kurang dimanfaatkan dalam mendukung pembelajaran.

d. Kurangnya pemahaman terhadap sistem informasi yang ada 
3. Peluang (Opportunities)

a. Prioritas pemerintah untuk membangun infrastruktur membuka peluang untuk akses pembangunan yang lebih baik

b. Kebutuhan akan jasa instansi pendidikan akan terus berlangsung dalam waktu yang lama

c. Tingginya minat orang tua dan masyarakat untuk menyekolahkan anaknya

d. Kerja sama dan kemitraan sekolah

4. Ancaman (Threat)

a. Pesatnya pertumbuhan sekolah dan lembaga pelatihan/kursus yang mendorong ketatnya persaingan

b. Perubahan situasi sosial, politik dan ekonomi yang dapat mempengaruhi kebijakan pemerintah pusat/daerah

c. Pertumbuhan teknologi informasi yang sangat cepat

d. Meningkatnya harga barang dan jasa

\subsection{Analisis TOWS}

Analisis TOWS terdapat strategi untuk peningkatan kelemahan yang ada pata Teknologi Informasi dan Komunikasi. Strategi lengkap terdapat pada tabel 1

Tabel 1. hasil Analisis TOWS

\section{SO}

1. Pengembangan kerjasama

2. Meningkatkan pelayanan siswa atau pelanggan

3. Pengembangan program diklat

4. Meningkatkan SIM yang terintegrasi

\section{WO}

1. Meningkatkan pemanfaatan layanan teknologi informasi

2. Penataan Manajemen

3. Meningkatkan pelayanan kepada siswa

\begin{tabular}{|c|c|}
\hline ST & WT \\
\hline $\begin{array}{l}\text { 1. Meningkatkan fasiltas Lab dan } \\
\text { internet untuk mendapat kualitas } \\
\text { pembelajarann }\end{array}$ & $\begin{array}{l}\text { 1. Menghindari pindahnya tenaga } \\
\text { pedidik berpenglaman ke instansi } \\
\text { lain }\end{array}$ \\
\hline 2. Pengembangan kerjasama & 2. Meningkatkan kualitas SDM baik \\
\hline $\begin{array}{l}\text { 3. Peningkatan mutu pendidikan } \\
\text { dengan pencapaian nilai akreditasi } \\
\text { yang baik dengan cara } \\
\text { meningkatkan SDM }\end{array}$ & $\begin{array}{ll}\text { tenaga pendidik/tenaga } \\
\text { kependidikan } \\
\text { 3. } \\
\text { Meningkatkan promosi }\end{array}$ \\
\hline
\end{tabular}

Hasil analisis dari Internal Factor Analysis Summary (IFAS) 
Tabel 2. Matrik Internal Factor Analysis Summary

\begin{tabular}{|c|c|c|c|}
\hline Faktor-faktor strategi Internal & Bobot & Rating & Nilai Skor \\
\hline Strength (S) : & 0,12 & 3 & \\
\hline $\begin{array}{l}\text { a. Kondisi sekolah yang kondusif dan lahan yang } \\
\text { cukup luas }\end{array}$ & 0,12 & 3 & 0,36 \\
\hline $\begin{array}{l}\text { b. Fasilitas belajar dan Laboratorium/bengkel } \\
\text { memadai }\end{array}$ & 0,12 & 3 & $\begin{array}{l}0,36 \\
0,36\end{array}$ \\
\hline $\begin{array}{l}\text { c. Tersedianya tenaga pendidik dan kependidikan } \\
\text { yang berkompeten }\end{array}$ & 0,12 & 3 & 0,36 \\
\hline $\begin{array}{l}\text { d. Memiliki fasilitas komputer yang cukup } \\
\text { mendukung untuk pengembangan IT } \\
\text { e. Jumlah peminat/siswa yang banyak }\end{array}$ & 0,08 & 3 & 0,24 \\
\hline Sub total & 0,56 & & 1,68 \\
\hline Weakness $(\mathrm{K})$ : & & & \\
\hline $\begin{array}{l}\text { a. Penggunaan jaringan komputer masih } \\
\text { kurang dimanfaatkan dalam mendukung } \\
\text { pembelajaran }\end{array}$ & 0,12 & 2 & 0,24 \\
\hline $\begin{array}{l}\text { b. Pemanfaatan website yang tidak optimal } \\
\text { c. Sebagian besar peralatan Laboratorium dan } \\
\text { bengkel rusak dan out of date }\end{array}$ & $\begin{array}{l}0,08 \\
0,08\end{array}$ & $\begin{array}{l}2 \\
2\end{array}$ & $\begin{array}{l}0,16 \\
0,16\end{array}$ \\
\hline $\begin{array}{l}\text { d. Kurangnya pemahaman terhadap sistem } \\
\text { informasi yang ada }\end{array}$ & 0.08 & 2 & 0,06 \\
\hline Sub Total & 0,36 & & 0,72 \\
\hline Total & 0,92 & & 2,4 \\
\hline
\end{tabular}

Didapat Nilai Total adalah : 2,4

Hasil analisis dari Eksternal Factor Analysis Summary (EFAS) 
Tabel 3. Matrik Eksternal Factor Analysis Summary

\begin{tabular}{|c|c|c|c|}
\hline Faktor-faktor strategi Eksternal & Bobot & Rating & Nilai Skor \\
\hline \multicolumn{4}{|l|}{ Opportunities (O) : } \\
\hline $\begin{array}{l}\text { a. Kebutuhan akan jasa instansi pendidikan akan } \\
\text { terus berlangsung dalam waktu yang lama }\end{array}$ & 0,18 & 3 & 0,54 \\
\hline $\begin{array}{l}\text { b. Tingginya minat orang tua dan masyarakat } \\
\text { untuk menyekolahkan anaknya }\end{array}$ & 0,13 & 3 & 0,36 \\
\hline $\begin{array}{l}\text { c. Memiliki gedung yang strategi berdasarkan } \\
\text { letak posisinya }\end{array}$ & 0,13 & 3 & 0,36 \\
\hline \multicolumn{4}{|l|}{ d. Kerja sama dan kemitraan sekolah } \\
\hline & 0,13 & 3 & 0,36 \\
\hline Sub total & 0,57 & & 1,62 \\
\hline \multicolumn{4}{|l|}{ Threat $(\mathbf{T}):$} \\
\hline $\begin{array}{l}\text { a. Pesatnya pertumbuhan sekolah dan lembaga } \\
\text { pelatihan/kursus yang mendorong ketatnya } \\
\text { persaingan }\end{array}$ & 0,13 & 2 & 0,24 \\
\hline \multirow{2}{*}{$\begin{array}{l}\text { b. Perubahan situasi sosial, politik dan ekonomi } \\
\text { yang dapat mempengaruhi kebijakan } \\
\text { pemerintah pusat/daerah }\end{array}$} & 0,09 & 2 & 0,16 \\
\hline & 0,09 & 2 & 0,18 \\
\hline $\begin{array}{l}\text { c. Pertumbuhan teknologi informasi yang sangat } \\
\text { cepat }\end{array}$ & 0,09 & 2 & 0,18 \\
\hline \multicolumn{4}{|l|}{ d. Meningkatnya harga barang dan jasa } \\
\hline Sub Total & 0,4 & & 0,8 \\
\hline Total & 0,97 & & 2,42 \\
\hline
\end{tabular}

Didapat nilai Total adalah : 2,42

Analisis menunjukkan bahwa untuk faktor Opportunity nilai skornya 1,62 dan faktor Threat 0,8 , selanjutnya nilai total skor dari masing-masing faktor dapat dirinci, Strength : 1,68 Weakness : 0,72 Opportunity : 1,62 dan Threat : 0,8 maka diketahui nilai Strength diatas nilai Weakness selisih $(+)$ 0,96 dan nilai Opportunity diatas nilai Threat $( \pm)$ 0,82 dari hasil identifikasi faktor-faktor tersebut maka dapat digambarkan dalam diagram SWOT, dapat dilihat pada gambar 8 . 


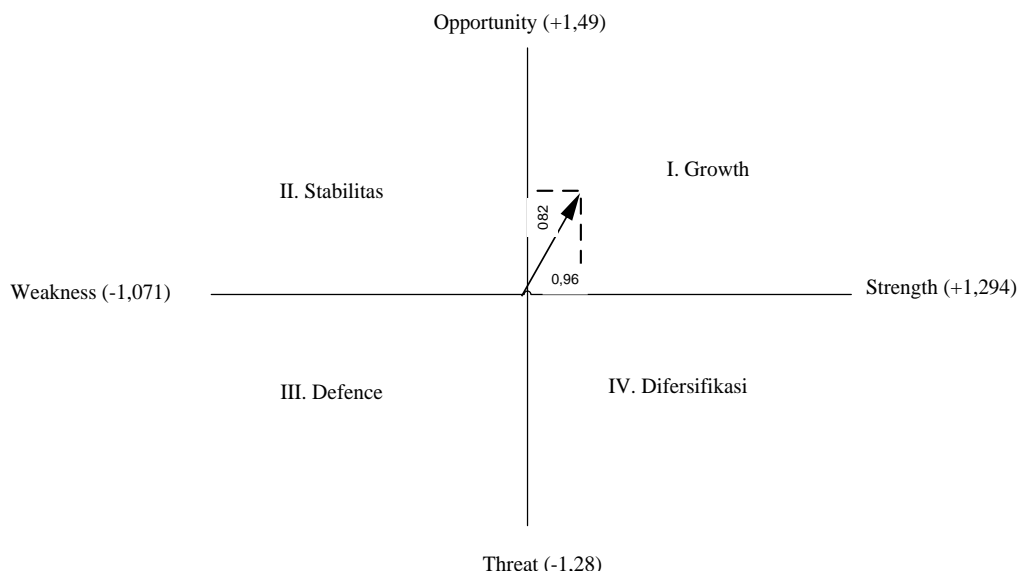

Gambar 8. diagram cartesius analisis SWOT SMK N 3 Lubuklinggau

Dari nilai total masing-masing faktor selain digambarkan dalam diagram SWOT juga digambarkan dalam rumusan matrik SWOT, dapat dilihat pada tabel 4

Tabel 4. Rumusan kombinasi strategi matrik SWOT

\begin{tabular}{cll}
\hline Eksternal & \multicolumn{1}{c}{ Strength } & \multicolumn{1}{c}{ Weakness } \\
\cline { 1 - 2 } Opportunity $(\mathrm{O})$ & $\begin{array}{l}\text { Strategi (SO) }: \\
=1,68+1,62=3,3\end{array}$ & $\begin{array}{l}\text { Strategi (WO) }: \\
=0,72+1,62=2,34\end{array}$ \\
\hline \multirow{2}{*}{ Threat $(\mathrm{T})$} & Strategi $(\mathrm{ST}):$ & Strategi $(\mathrm{WT}):$ \\
& $=1,68+0,8=2,48$ & $=0,72+0,8=1,52$ \\
\hline
\end{tabular}

Arah Pengelolaan Strategi dengan Analisis SWOT

Sesuai dengan Analisis TOWS yang melengkapi analisis SWOT, maka di dapat arah strategi pengelolaan Instansi Pendidikan, antara lain :

a. Meningkatkan pemanfaatan layanan teknologi informasi

b. Meningkatkan kualitas lulusan

c. Meningkatkan pelayanan kepada siswa

d. Meningkatkan fasiltas Lab dan internet untuk mendapat kualitas pembelajaran

e. Peningkatan mutu pendidikan dengan pencapaian nilai akreditasi yang baik dengan cara meningkatkan SDM

f. Meningkatkan promosi

g. Melakukan peningkatan usaha dengan pengembangan kompetensi keahlian 
h. Meningkatkan SIM yang terintegrasi

\section{Strategi SI/TI}

Dari hasil analisis SO,ST,WO,WT maka dihasilkan strategi yang dibagi dalam 7 kelompok strategi

Tabel 5. Keterkaitan antara Strategi bisnis, Aplikasi dan Kebutuhan Informasi

\begin{tabular}{|c|c|c|c|}
\hline No & Sasaran & Kriteria sukses & $\begin{array}{c}\text { kebutuhan } \\
\text { sistem Informasi }\end{array}$ \\
\hline 1 & $\begin{array}{l}\text { Menciptakan alternatif } \\
\text { strategis pembiayaan } \\
\text { dan membagi resiko } \\
\text { biaya }\end{array}$ & $\begin{array}{l}\text { Memaksimalkan } \\
\text { pengembangan pelayanan } \\
\text { jasa pendidikan SMK di } \\
\text { Kota Lubuklinggau }\end{array}$ & $\begin{array}{l}\text { Aplikasi } \\
\text { pengelolaan Data } \\
\text { Base SMK di Kota } \\
\text { Lubuklinggau }\end{array}$ \\
\hline 2 & $\begin{array}{l}\text { Membangun kinerja } \\
\text { SIM }\end{array}$ & $\begin{array}{l}\text { Kemudahan dalam } \\
\text { komunikasi untuk } \\
\text { mendukung pelayanan jasa } \\
\text { SMK di Kota Lubuklinggau }\end{array}$ & $\begin{array}{l}\text { sistem monitoring } \\
\text { kinerja SIM }\end{array}$ \\
\hline 3 & $\begin{array}{l}\text { Meningkatkan pangsa } \\
\text { pasar } \\
\text { pembentukan } \\
\text { company image }\end{array}$ & $\begin{array}{l}\text { kepercayaan pelanggan } \\
\text { meningkat }\end{array}$ & $\begin{array}{l}\text { Sistem monitoring } \\
\text { SDM berprestasi } \\
\text { (evaluasi diri) }\end{array}$ \\
\hline 4 & $\begin{array}{l}\text { Mampu membuat } \\
\text { sistem informasi yang } \\
\text { sesuai dengan } \\
\text { perubahan } \\
\text { perkembangan } \\
\text { teknologi informasi }\end{array}$ & $\begin{array}{l}\text { Keamanan dan kehandalan } \\
\text { yang optimal }\end{array}$ & $\begin{array}{l}\text { Sistem administrator } \\
\text { monitoring }\end{array}$ \\
\hline 5 & $\begin{array}{l}\text { Menghasilkan lulusan } \\
\text { yang mampu dan } \\
\text { handal bagi SDM } \\
\text { industri/usaha }\end{array}$ & $\begin{array}{l}\text { Pengakuan di dunia } \\
\text { usaha/industri }\end{array}$ & $\begin{array}{l}\text { Pengembangan } \\
\text { sistem pengajaran } \\
\text { online }\end{array}$ \\
\hline 6 & $\begin{array}{l}\text { Pemberdayaan staff } \\
\text { secara tepat }\end{array}$ & $\begin{array}{l}\text { Kenyamanan dan jaminan } \\
\text { kerja }\end{array}$ & $\begin{array}{l}\text { Sistem monitoring } \\
\text { kesejahteraan staff }\end{array}$ \\
\hline 7 & $\begin{array}{lr}\text { Peningkatan } & \\
\text { kompetensi } & \text { SDM } \\
\text { SMK di } & \text { Kota } \\
\text { Lubuklinggau } & \end{array}$ & $\begin{array}{l}\text { Produktifitas staff lebih } \\
\text { tinggi }\end{array}$ & $\begin{array}{l}\text { Sistem monitoring } \\
\text { SDM berprestasi } \\
\text { (evaluasi diri) }\end{array}$ \\
\hline
\end{tabular}




\section{Strategi Growth}

Dengan mengacu pada analisis SWOT yang telah dibahas maka strategi yang digunakan adalah strategi growth fungsional. Strategi growth ini merupakan situasi yang sangat menguntungkan. Sekolah tersebut memiliki peluang dan kekuatan sehingga dapat memanfaatkan peluang yang ada. Strategi yang harus diterapkan dalam kondisi ini adalah mendukung kebijakan pertumbuhan yang agresif (growth oriented strategy)

\section{Rekomendasi Strategi SI / TI}

a. Aplikasi Strategis

Aplikasi yang sangat kritis untuk keberhasilan Sekolah di masa datang, diperlukan untuk inovasi berkelanjutan, integrasi vertikal, dan memberikan nilai tambah dikelompokkan sebagai aplikasi strategis.

Tabel 6. Daftar Aplikasi Strategis

\begin{tabular}{lll}
\hline No & Kebutuhan Sistem Informasi & \multicolumn{1}{c}{ keterangan } \\
\hline 1 & Sistem pengelolaan SAP & $\begin{array}{l}\text { Diperlukan untuk mendukung } \\
\text { pengambilan keputusan pengajaran guru }\end{array}$ \\
\hline 2 & Sistem administrator jaringan & $\begin{array}{l}\text { Untuk mengoptimalkan internet, menjaga } \\
\text { kinerja jaringan komputer SMK N 3 } \\
\text { Lubuklinggau }\end{array}$ \\
\hline
\end{tabular}

3 Pengelolaan database penelitian Mendukung prakerin dan magang

\begin{tabular}{|c|c|c|}
\hline 4 & Sistem monitoring kinerja & Monitoring alumni \\
\hline 5 & $\begin{array}{l}\text { Pengembangan sistem berbasis } \\
\text { android }\end{array}$ & Alat promosi yang efektif dan efisien \\
\hline 6 & Sistem vidio conference & Mendukung sistem belajar mengajar \\
\hline 7 & $\begin{array}{l}\text { Pengembangan pembelajaran } \\
\text { online }\end{array}$ & Mendukung peningkatan kualitas siswa \\
\hline 8 & Sistem terintegrasi & $\begin{array}{l}\text { Menghubungkan semua aplikasi pada } \\
\text { setiap kompetensi keahlian }\end{array}$ \\
\hline
\end{tabular}

\section{b. Aplikasi Operasional Utama}

Aplikasi yang digunakan saat ini dan diperlukan untuk inovasi, utilisasi sumber daya, dan menghasilkan produk bermutu tinggi digolongkan sebagai aplikasi operasional utama. 
Tabel 7. Daftar Aplikasi Operasional Utama

\begin{tabular}{|c|c|c|}
\hline No & Kebutuhan Sistem Informasi & keterangan \\
\hline 1 & Sistem absensi online & $\begin{array}{l}\text { Membantu pengawasan dan pembinaan } \\
\text { disiplin pegawai }\end{array}$ \\
\hline 2 & $\begin{array}{l}\text { Aplikasi perkantoran umum dan } \\
\text { basis data }\end{array}$ & $\begin{array}{l}\text { Diperlukan untuk operasional sehari-hari } \\
\text { SMK N } 3 \text { Lubuklinggau }\end{array}$ \\
\hline 3 & $\begin{array}{l}\text { Operasional proses berbasis } \\
\text { sistem }\end{array}$ & Perlu jaringan dan sistem online \\
\hline
\end{tabular}

c. Aplikasi Pendukung

Aplikasi yang bermanfaat tapi tidak kritis terhadap keberhasilan, biasanya diperlukan untuk efisiensi dan mempertahankan mutu disebut aplikasi pendukung

Tabel 8. Daftar Aplikasi Pendukung

\begin{tabular}{llll}
\hline No & Kebutuhan Sistem Informasi & \multicolumn{1}{c}{ keterangan } \\
\hline 1 & Aplikasi perpustakaan & Mendukung proses membaca dan belajar \\
\hline 2 & Aplikasi monitoring keuangan & Mengoptimalkan pengunaan kas \\
\hline 3 & $\begin{array}{l}\text { Aplikasi pengelolaan sarana dan } \\
\text { prasarana }\end{array}$ & $\begin{array}{l}\text { Mendukung pendataan sarana dan } \\
\text { prasaran pelayanan jasa pendidikan }\end{array}$ \\
\hline 4 & Penjadwalan audit otomatis & $\begin{array}{l}\text { Salah satru upaya penjaminan mutu } \\
\text { pelayanan jasa pendidikan }\end{array}$ \\
\hline 5 & $\begin{array}{l}\text { Pengawasan pelaksanaan tindak } \\
\text { lanjut audit }\end{array}$ & $\begin{array}{l}\text { Menjaga komitmen implementasi sistem } \\
\text { mutu }\end{array}$ \\
\hline 6 & $\begin{array}{l}\text { Sistem poling tentang kepuasan } \\
\text { pegawai }\end{array}$ & $\begin{array}{l}\text { Untuk mendapatkan data obyektif dalam } \\
\text { rangka pengembangan SDM }\end{array}$ \\
\hline 7 & Sistem basis data guru & $\begin{array}{l}\text { Membantu pengawasan dan pembinaan } \\
\text { disiplin guru }\end{array}$ \\
\hline 8 & $\begin{array}{l}\text { Penulusuran dan pencatatan } \\
\text { akses sistem }\end{array}$ & $\begin{array}{l}\text { Memelihara dan menjaga keamanan } \\
\text { sistem }\end{array}$ \\
\hline
\end{tabular}

d. Aplikasi Potensi Tinggi 
Aplikasi yang mungkin penting untuk keberhasilan SMK N 3 Lubuklinggau dimasa depan, dan biasanya diperlukan untuk riset dan perencanaan proses, integrasi, dan pengendalian biaya disebut aplikasi potensi tinggi.

Tabel 9. Daftar Aplikasi Potensi Tinggi

\begin{tabular}{|c|c|c|}
\hline No & Kebutuhan Sistem Informasi & keterangan \\
\hline 1 & $\begin{array}{l}\text { Sistem monitoring } \\
\text { berprestasi }\end{array}$ & $\begin{array}{l}\text { Menyiapkan sistem reward berdasarkan } \\
\text { kompetensi pegawai }\end{array}$ \\
\hline 2 & Sistem monitoring kinerja SIM & $\begin{array}{l}\text { Meningkatkan kuantitas dan kualitas } \\
\text { kinerja sistem informasi }\end{array}$ \\
\hline 3 & $\begin{array}{l}\text { Otomatisasi proses pelayanan } \\
\text { jasa pendidikan }\end{array}$ & Perlu sistem Online \\
\hline 4 & $\begin{array}{l}\text { Penyediaan informasi secara } \\
\text { online }\end{array}$ & Promosi tanpa batas waktu dan tempat \\
\hline 5 & Aplikasi $W e b$ & $\begin{array}{l}\text { Mendukung basis teknologi intranet dan } \\
\text { internet }\end{array}$ \\
\hline
\end{tabular}

\section{Kesimpulan}

Berdasarkan hasil penelitian dengan metode analisis SWOT, didapat data sebagai berikut : nilai total IFAS yaitu 2,4 dan nilai total EFAS adalah sebesar 2,42, maka menempatkan SMK di lingkungan Kota Lubuklinggau pada posisi strategis. Pada masa yang akan datang penggunaan teknologi sistem informasi akan sangat di butuhkan untuk menunjang keberhasilan tujuan organisasi di bidang pendidikan. Penelitian ini menghasilkan gambaran lingkungan internal dan eksternal sebagai analisis awal untuk merujuk pada usulan perencanaan strategi pengembangan teknologi informasi dan komunikasi (TIK) yang dapat dijadikan panduan pengembangan teknologi informasi sehingga dapat meningkatkan kinerja dan nilai kompetitif sekolah.

\section{Referensi}

Akbar, M., \& Antoni, D. (2019). E-supply chain management value concept for the palm oil industry. Jurnal Sistem Informasi, 15(2), 15-29.

Antoni, D., Akbar, M., \& Fatoni, F. (2018). Electronic government Rukun Tetangga model. Jurnal Sistem Informasi, 14(2), 64-73.

Antoni, D., Fikari, D., Akbar, M., \& Jie, F. (2018). The readiness of palm oil industry in enterprise resource planning. Telkomnika, 16(6).

Antoni, D., Jie, F., \& Abareshi, A. (2020). Critical factors in information technology capability for enhancing firm's environmental performance: Case of Indonesian ICT sector. International Journal of Agile Systems and Management, 13(2), 15-181.

Ariana, S., Azim, C., \& Antoni, D. (2020). Clustering of ICT human resources capacity in the 
implementation of E-government in expansion area: A case study from Pali regency. Cogent Business \& Management, 7(1), 1754103.

Fauzi, F., Dencik, A. B., \& Asiati, D. I. (2019). Metodologi Penelitian Untuk Manajemen dan Akuntansi. Jakarta: Salemba Empat.

Rangkuti., \& Freddy. (2009). Strategi Promosi yang Kreatif dan Analisis Kasus Integrated Marketing Communication. Jakarta : PT. GramediaPustakaUtama

Ward, J., \& Peppard, J., (2002). Strategic Planning for Information System 3 ed, England:John Wiley \& Sons.

\section{Copyrights}

Copyright for this article is retained by the author(s), with first publication rights granted to the journal.

This is an open-access article distributed under the terms and conditions of the Creative Commons Attribution license (http://creativecommons.org/licenses/by/4.0/) 